\title{
Microstrip multi-stopband filter based on tree fractal slotted resonator
}

\author{
Manju Bhaskar, Thomaskutty Mathew \\ Department of Elctronics, School of Technology and Applied Sciences, India
}

\begin{tabular}{l} 
Article Info \\
\hline Article history: \\
Received Sep 1, 2018 \\
Revised Mar 27, 2019 \\
Accepted Apr 10, 2019 \\
\hline
\end{tabular}

\section{Keywords:}

Bandstop filter

Modes

Multi-stopband

Patch resonator

Tree fractal

\begin{abstract}
This paper presents the design and development of a new microstrip multistopband filter based on tree fractal slotted resonator. A single square patch with tree fractal slots of different iterations are employed for realizing dual stopband and tri-stopband filters. The tree fractal slotted resonators are generated from conventional square patch using an iterative tree fractal generator method. First, second and third level iterations of the tree fractal slot resonator are used to design dual and tri-stopband filters respectively. The first level iteration introduced for the tree fractal slot realizes dual bands at $2.64 \mathrm{GHz}$ and $3.61 \mathrm{GHz}$ while the second level iteration provides better stopband rejection and insertion loss at $2.57 \mathrm{GHz}$ and $3.56 \mathrm{GHz}$. The tristopband filter generates three resonance frequencies at $1.53 \mathrm{GHz}, 2.53 \mathrm{GHz}$ and $3.54 \mathrm{GHz}$ at third level iteration. By varying the slot length and width of the tree fractal slot, the resonant frequencies can be adjusted, and stopbands of the proposed filter can be tuned for the desired unwanted frequency to be rejected. The proposed narrowband filters find application in removing the interference of GPS and Wi-Max narrowband signals from the allotted bands of other wireless communication systems.
\end{abstract}

Copyright () 2019 Institute of Advanced Engineering and Science. All rights reserved.

\section{Corresponding Author:}

Thomaskutty Mathew,

Department of Electronics,

Reader, School of Technology and Applied Sciences,

Edappally, Kochi, India.

Email: drtkmathew@gmail.com

\section{INTRODUCTION}

The requirement of multi-stopband filters is increasing day by day as the radio frequency transceiver front-ends with enhanced performance and compactness is necessary for the advancement of wireless communication technologies. Narrow bandwidth, compact size, low weight and reduced loss are the main advantages of multiband patch filters [1]. Microstrip multi-stopband filter is an important component of a wireless communication transceiver for the removal of multiple bands simultaneously, as the electronic devices operating over a wide frequency range has to suppress the presence of spurious and harmonic signals.

Conventional multi-stopband filters are realized by cascading different stopband filters causing the circuit size to increase which is not suitable for the compact modern communication systems. Various designs in the literature for microstrip multi-stopband filter includes stub loaded stepped impedance resonators [2, 3], dual mode square loop resonator filters $[4,5]$, stub loaded resonator filters $[6,7]$ and defected microstrip resonator filter [8] methods. Connecting various stub loaded resonators to realize a multistop band causes an increase in insertion loss and circuit size of the filter. Radiation loss from the backside of the defected ground filters needs additional structures under the ground plane which increase the complexity in the design and weight of the filter structure.

Apart from these design methods, fractal resonators are finding applications in realizing multiband filters as the self-similarity property of fractal geometries can be successfully applied to the design of multi- 
band filters while the space-filling property can be utilized for miniaturization. In fractal structures, each subsection has the characteristics of the whole structure in a smaller scale [9]. The complex iterative nature of fractals which is responsible for multiband behaviour is exploited on a large scale for the designing of microwave devices.In [10] Federico Caramanica reported a miniaturized multi-stopband filter based on Hilbert space-filling curve, capable of eliminating multiple interference signals. A dual-band left-handed metamaterial fabricated using tree-shaped fractal is investigated by $\mathrm{Xu} \mathrm{He-Xiu} \mathrm{et} \mathrm{al.} \mathrm{[11].} \mathrm{An} \mathrm{H-fractal}$ wideband microstrip filter with multi-passbands and a tuned notch band for wireless communication is reported by Patin et al. [12].

Trindade et al. in [13] reported the analysis of a 2-D periodic array of metal Durer's pentagon prefractals patch elements for attaining dual stopband filter response. Peano fractal resonator structures of two different dimenions are aligned and coupled to either sides of the transmission line for attaining dual stopband response in [14]. The reported work in [15] comprises more than one minkowski fractal based open loop ring resonators with different iteration levels in the same filter structure to generate tri-stopband response. In Ahmed et al. [16] reported minkowski fractal geometry applied to the conventional triangular resonator to design a stopband filter.A stopband filter designed using minkowski fractal ring resonators and open stub resonators for leakage reduction in microwave ovens is reported in [17]. In [18] a quasi fractal multi stopband filter is reported with narrow fractional bandwidth. Designing simple multi-stopband filters with reduced number of coupling structures and stubs is an inevitable requirement for modern wireless communication systems. Tree fractal is a simple fractal structure which provides flexibility in tuning the filter characteristics and multibandstop filters based on these fractal structures are not reported in literature.

This paper presents the design and development of multi-stopband filters based on tree fractal slotted resonators. By introducing various levels of tree fractal iteration on the slots, it is observed that multiple resonant peaks are obtained corresponding to the modes excited on a simple square patch. Dual stopband and tri-stopband responses are generated by increasing the fractal iteration on the same structure without additional coupling or added structures.

\section{TREE FRACTAL GENERATION PROCESS}

The schematics showing the generation process of the tree fractal structure is given in Figure 1 . The procedure to create a tree fractal starts off with a line of length $L$ and width $d$ as in Figure 1(a) which acts as the generator. At the first level of iteration, the length $\mathrm{L}$ is divided into three equal segments. A line segment with one third of the length $\mathrm{L}$ is introduced perpendicular to the initial line $\mathrm{L}$ at the first point of division and also a segment with the same length is positioned at the second point of division, again perpendicular to the initial line L but in the opposite direction. Figure 1(b) depicts the structure after first iteration. This forms the basic step for the formation of the tree fractal.

Fractal dimension $\mathrm{D}$ is given by (1). $\mathrm{N}$ is the number of self-similar line segments after each iteration level and $\mathrm{r}$ is the scaling factor [19]. The fractal dimension after level-1 iteration is $\log 5 / \log 3=1.456$. After the first level iteration there are five equal line segments. In the consecutive iteration process, each segment is considered as the initial line segment and following the same procedure will attain the second iterated structure as in Figure 1(c). The fractal dimension after second level iteration is 2.929. Further the third level iteration results in the fractal structure as shown in Figure 1(d) with a fractal dimension of 4.394 .

$$
D=\frac{\log (N)}{\log (r)}
$$

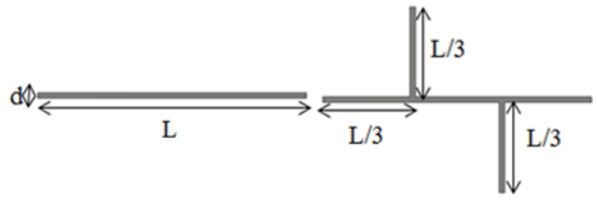

(a)

(b)

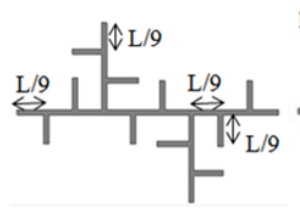

(c)

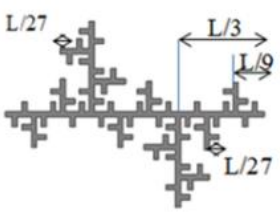

(d)

Figure 1. Schematics of the formation of the tree fractal geometry

(a) generator (b) First level iteration (c) second level iteration (d) third level iteration 


\section{FILTER DESIGN AND LAYOUT}

The proposed filter structure has a feeding microstrip transmission line with width $\mathrm{w}$ and height $\mathrm{h}$. A single square patch with various levels of tree fractal slot is introduced on the top side and is placed in proximity to the transmission line with a coupling gap of $\mathrm{g}$. The various filter structures are given in Figure 2 (a-d). For $w / h \geq 2$ and characteristics impedance $Z_{\text {line }}=50 \Omega$ for the matching conditions on input and output ports, the expression for $\mathrm{W}$ of the feeding microstrip line is given by (2) where $\varepsilon_{\mathrm{r}}$ is the relative dielectric constant of the substrate [1].

$$
w=\frac{2 h}{\pi}\left\{\left(\frac{60 \pi^{2}}{Z_{\text {line }} \sqrt{\varepsilon_{r}}}-1\right)-\ln \left(2 \frac{60 \pi^{2}}{Z_{\text {line }} \sqrt{\varepsilon_{r}}}-1\right)+\frac{\varepsilon_{r}-1}{2 \varepsilon_{r}}\left[\ln \left(\frac{60 \pi^{2}}{Z_{\text {line }} \sqrt{\varepsilon_{r}}}-1\right)+0.39-\frac{0.61}{\varepsilon_{r}}\right]\right\}
$$

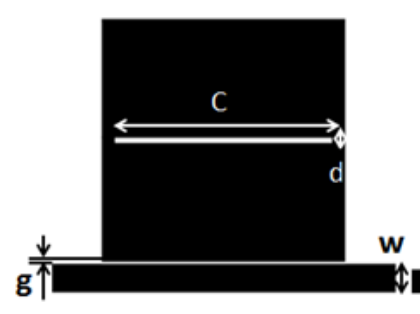

(a)

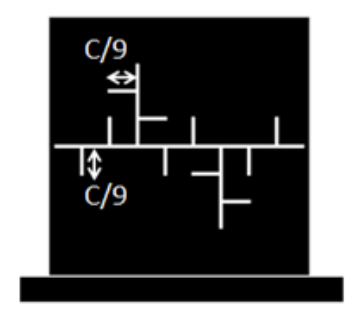

(c)

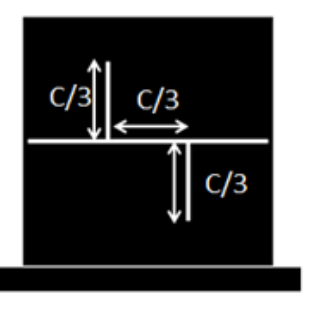

(b)

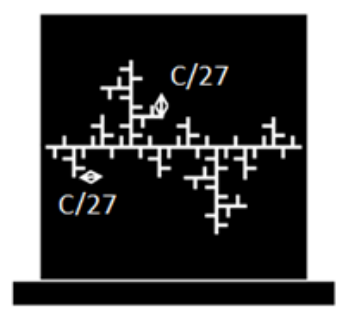

(d)

Figure 2. The tree fractal slotted square patch filter structures with various levels of iteration on the initial slot (a) zeroth iteration (b) first level iteration (c) second level iteration (d) third level iteration

The electromagnetic fields in the square patch resonator can be explained in terms of $\mathrm{TM}_{\mathrm{mn} 0}^{\mathrm{Z}}$ modes [1] with $\mathrm{Z}$ perpendicular to the ground of the plane. The resonant frequency is given in (3) where a and $b$ are the sides of the square patch resonator and $\mu_{\mathrm{r}}$ is the relative permeability of the substrate. Two fundamental modes $\mathrm{TM}_{100}$ and $\mathrm{TM}_{010}$ and an infinite number of higher order modes are supported by the square patch resonator $[1,20]$. The first higher order mode is $\mathrm{TM}_{110}$.

$$
f_{m n_{0}}=\frac{c}{2 \Pi \sqrt{\mu_{r} \varepsilon_{r}}} \sqrt{\left(\frac{m \pi}{a}\right)^{2}+\left(\frac{n \pi}{b}\right)^{2}}
$$

\section{RESULTS AND DISCUSSION}

The filters are realized on RT Duroid 5880 substrate with $\epsilon_{\mathrm{r}}=2.2$ and height $\mathrm{h}=0.79 \mathrm{~mm}$. The design and simulations are performed in CST Microwave Studio to get optimized parameters. For realizing the single band zeroth iteration tree fractal slotted stopband filter, a slot c with length $18 \mathrm{~mm}$ and width $\mathrm{d}=0.4 \mathrm{~mm}$ is introduced on the top side of the patch. Figure 3(a) shows the simulated and measured $S_{11}$ and $S_{21}$ responses which resonates at $2.8 \mathrm{GHz}$. For the first level iterated tree fractal filter, dual stopbands are obtained at $2.64 \mathrm{GHz}$ and $3.61 \mathrm{GHz}$ as depicted in Figure 3(b). Further the next level iteration improves the rejection levels of the dual stopbands as shown in Figure 4(a). Filter resonates at $2.57 \mathrm{GHz}$ and 3.56 GHz. Figure 4(b) gives the simulated and measured $S_{11}$ and $S_{21}$ responses of the tri-stopband filter resonances at $1.57 \mathrm{GHz}, 2.53 \mathrm{GHz}$ and $3.54 \mathrm{GHz}$. Table 1 summarises the stopband performances of the filters with quality factor, fractional bandwidth (FBW), rejection levels and insertion loss obtained at the resonant bands. 


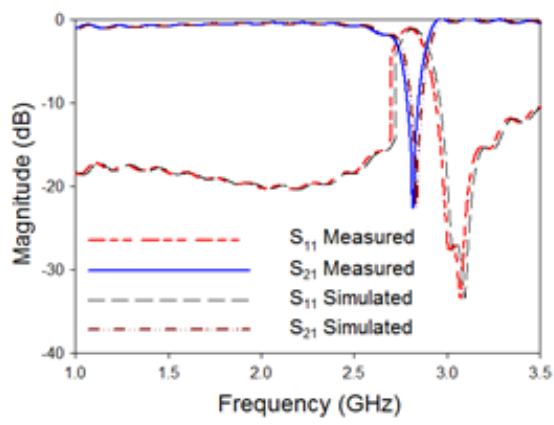

(a)

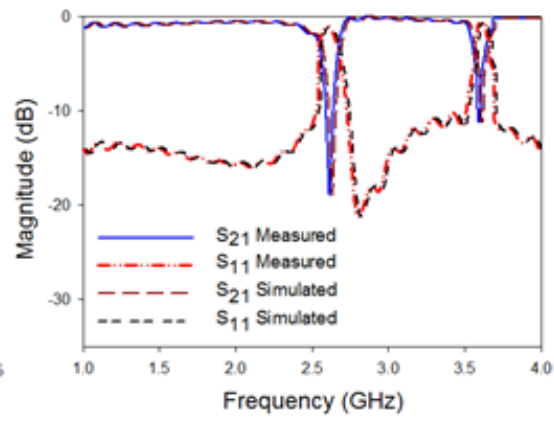

(b)

Figure 3. Simulated and Measured $S_{11}$ and $S_{21}$ responses for

(a) 0th level iterated filter (b) 1 st order iterated filter

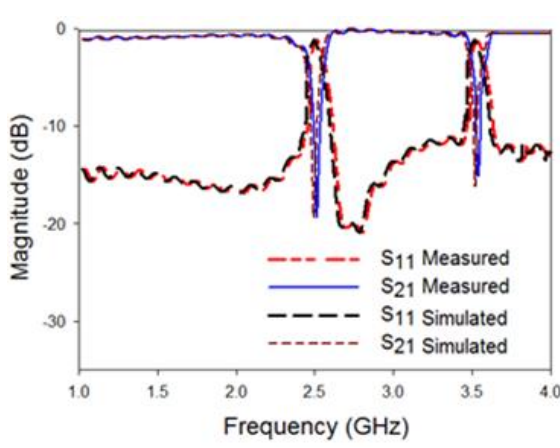

(a)

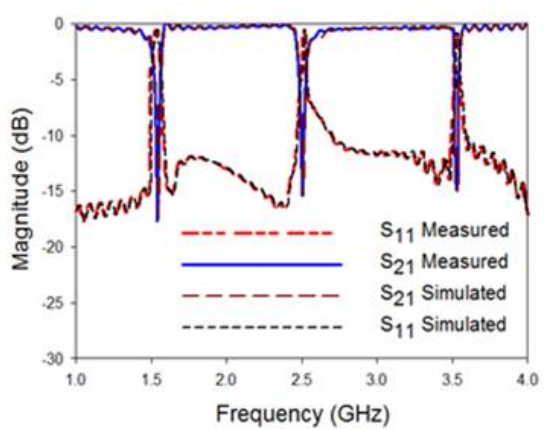

(b)

Figure 4. Simulated and measured $S_{11}$ and $S_{21}$ responses for (a) $2^{\text {nd }}$ level iterated filter (b) $3^{\text {rd }}$ level iterated filter

Table1. Measured performance parameters of the proposed filters

\begin{tabular}{|c|c|c|c|c|c|}
\hline \multirow[t]{2}{*}{ Filter Type } & \multicolumn{5}{|c|}{ Performance Parameters } \\
\hline & $\begin{array}{c}\text { Stopband } \\
(\mathrm{GHz})\end{array}$ & $\begin{array}{c}-3 \mathrm{~dB} F B W \\
(\%)\end{array}$ & $\begin{array}{l}\text { Rejection Level } \\
(\mathrm{dB})\end{array}$ & $\begin{array}{l}\text { Insertion Loss } \\
(\mathrm{dB})\end{array}$ & Quality Factor \\
\hline Zeroth Iteration & 2.8 & 5.69 & 22.8 & 0.81 & 17.5 \\
\hline First Level Iteration & $2.6 / 3.59$ & $4.49 / 2.78$ & $18.9 / 11.1$ & $0.95 / 0.97$ & $20.03 / 35.9$ \\
\hline Second Level Iteration & $2.57 / 3.5$ & $4.04 / 2.56$ & $19.4 / 15.2$ & $0.96 / 0.89$ & $24.7 / 38.9$ \\
\hline Third Level Iteration & $1.57 / 2.5 / 3.5$ & $3.25 / 2.4 / 1.1$ & $17.9 / 15.8 / 15.2$ & $0.50 / 0.52 / 0.77$ & $30.7 / 41.6 / 90.9$ \\
\hline
\end{tabular}

For the zeroth level single stopband filter, $\mathrm{TM}^{\mathrm{Z}}{ }_{010}$ mode resonates along the width of the patch structure at $2.8 \mathrm{GHz}$. Both in first and second level iterated filters, the increased slot length in the direction perpendicular to the initial slot $c$ excites the next resonant mode $\mathrm{TM}^{\mathrm{Z}}{ }_{100}$ along with $\mathrm{TM}^{\mathrm{Z}}{ }_{010}$ thereby producing the second resonance. $\mathrm{TM}^{\mathrm{Z}}{ }_{010}$ mode excites the first resonant peak and $\mathrm{TM}^{\mathrm{Z}}{ }_{100}$ mode which resonates along the length of the patch excites the second peak. By introducing the third level iteration on the tree fractal slot, the first higher order mode $\mathrm{TM}_{110}^{Z}$ got excited along with the dominant modes $\mathrm{TM}_{100}^{Z}$ and $\mathrm{TM}^{\mathrm{Z}}{ }_{010}$ in the square patch. The surface current flow for this mode took a shorter resonant path than the first two modes and traverses in both directions on the patch. The surface current distributions at the three resonant frequencies for the tri-stopband filter are shown in Figure 5(a-c).

The filters discussed have the very important characteristics that their stopband resonant frequencies are tunable by varying the slot length $\mathrm{c}$ or width d. Figure 6(a) shows the effect of varying slot length $\mathrm{c}$ for the zeroth order tree fractal stopband filter. From the simulated $S_{21}$ results for three different values of slot length $23 \mathrm{~mm}, 24 \mathrm{~mm}$ and $25 \mathrm{~mm}$ it is evident that as the slot length is increased, the resonant peaks shifts to the lower frequency side from $2.47 \mathrm{GHz}, 2.39 \mathrm{GHz}$ and $2.30 \mathrm{GHz}$ respectively. As the slot length increases, the increased length seen by the electric current causes a leftward shift or reduction in the resonant frequency. The slot is increasing in area both horizontally in $\mathrm{x}$ direction and vertically in y direction after each iteration. Figure 6(b) shows the Y slot in vertical or y direction and $\mathrm{H}$ slot in horizontal or $\mathrm{x}$ direction after third level iteration on the initial slot. 


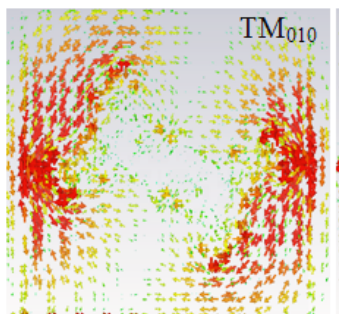

(a)

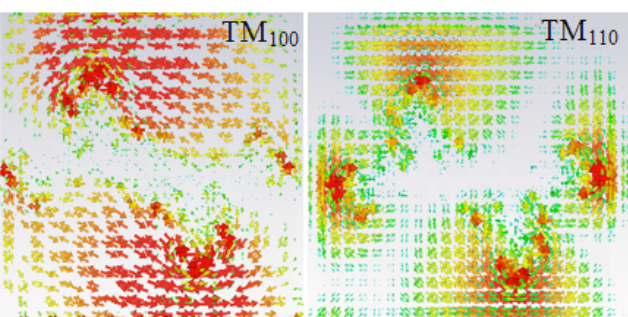

(b) (c)

Figure 5. Surface current distributions of the tri-stopband filter (a) at $1.53 \mathrm{GHz}$ (b) at $2.53 \mathrm{GHz}$ (c) at $3.54 \mathrm{GH}$

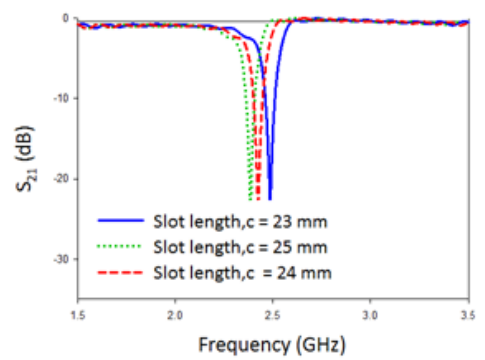

(a)

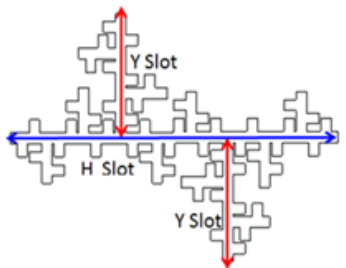

(b)

Figure 6. (a) Effect of varying slot length c on the resonant frequency of the zeroth level tree fractal slotted filter (b) Topology indicating the horizontally and vertically oriented slot after third level iteration

The effect of slot width on the resonance behaviour of the filter is shown in Figure 7. By only varying the width, $\mathrm{d}$ of the $\mathrm{H}$ slot from $1 \mathrm{~mm}$ to $.4 \mathrm{~mm}$ it is observed from Figure 7 (a) that the first resonant frequency $\mathrm{f}_{1}$ shifts to higher frequency side. This indicates that the $\mathrm{TM}^{\mathrm{Z}} \mathrm{O}_{010}$ mode causing the first resonance has to transverse a lesser current path for $d=.4 \mathrm{~mm}$ compared to $\mathrm{d}=1 \mathrm{~mm}$. As shown in Figure 7(b) if the width of the $\mathrm{Y}$ slot alone is varied from $1 \mathrm{~mm}$ to $.4 \mathrm{~mm}$ it is observed that the second resonant frequency $\mathrm{f}_{2}$ of the filter shifts to higher frequency side. $\mathrm{TM}^{\mathrm{Z}}{ }_{100}$ mode traversing in $\mathrm{x}$ direction of the patch finds a reduced path and correspondingly the resonant peak shifts to higher frequency side. It is obvious that the first and second bands can be tuned individually by varying the width of $\mathrm{H}$ or $\mathrm{Y}$ slot respectively. Also it is understood from $S_{21}$ results of Figure 7(c) that if we vary the slot width from $1 \mathrm{~mm}$ to $.3 \mathrm{~mm}$, the first, second and third resonances $\mathrm{f}_{1}, \mathrm{f}_{2}$ and $\mathrm{f}_{3}$ respectively shifts to the upper frequency side. All stopbands of the reported filters fall between $1.5 \mathrm{GHz}$ and $3.6 \mathrm{GHz}$ which finds application in modern wireless communication. The proposed filter in this work generates tri-stopband response by increasing the iteration level of the tree fractal slot on a single square patch resonator as compared to $[14,15]$ there by reducing the number of resonant structures coupled to the transmission line. Figure $8(\mathrm{a}-\mathrm{c})$ shows the photographs of the fabricated filters.

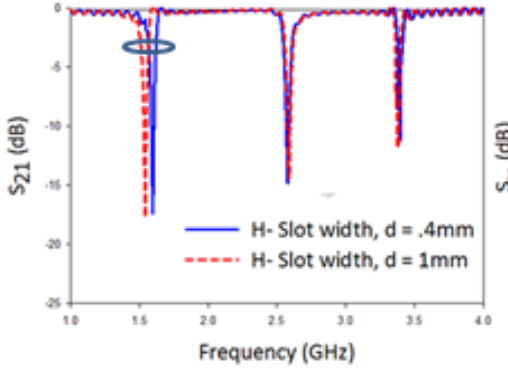

(a)

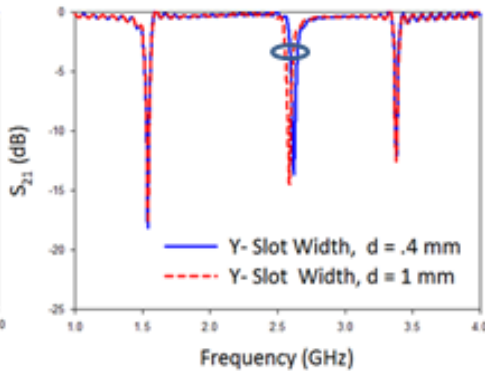

(b)

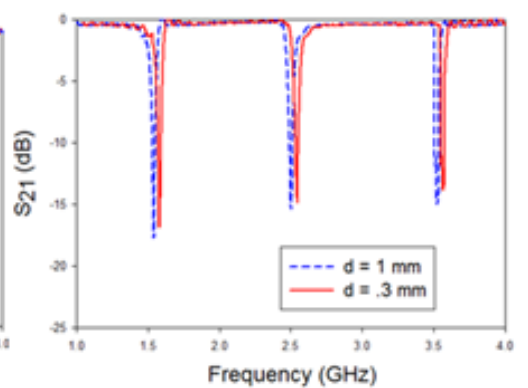

(c)

Figure 7. (a) Effect of varying only the width of $\mathrm{H}$ slot on resonant frequencies (b) Effect of varying only the width of Y slot on resonant frequencies (c) Effect of varying the slot width on the resonant frequencies. 


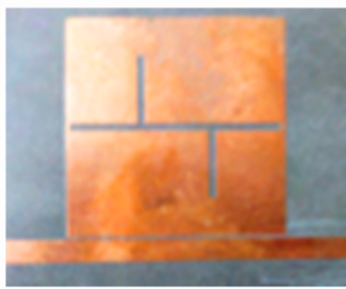

(a)

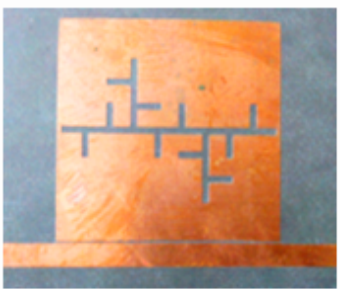

(b)

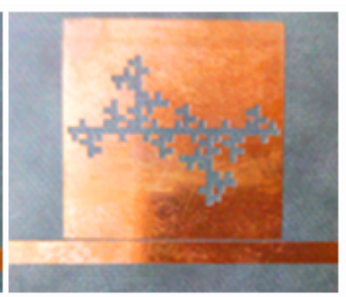

(c)

Figure 8. Photographs of the fabricated tree fractal slotted filters (a) $1^{\text {st }}$ level iteration (b) $2^{\text {nd }}$ level iteration (c) $3^{\text {rd }}$ level iteration

\section{CONCLUSION}

Design and development of microstrip multi-stopband filters based on tree fractal slotted resonator are presented. Dual stopband and tri-stopband filters have good rejection levels at the stopbands and have insertion losses less than $1 \mathrm{~dB}$. Additionally, the resonant peaks of the stopbands can be tuned by adjusting the length or width of the slot. Further by varying the width of the slot either in horizontal or vertical direction, the resonance of first or second stopband can be tuned individually. Mutiband responses are generated by increasing the tree fractal slotted iterations on a single square patch without adding any additionl structures, thus making the filter structure simple. All the filter designs are simple in structure and narrowband .The proposed bandstop filters find application in removing the interferences of GPS (1.57 GHz) and Wi-Max (2.5 GHz and $3.5 \mathrm{GHz})$ signals from other communication sysems like Wi-Fi, Zigbee and Bluetooth which are used in household appliances and other devices.All the filter designs are verified from the measurement and the results are in good agreement with the simulation results.

\section{REFERENCES}

[1] Jia-Sheng Hong and M. J. Lancaster, "Microstrip filters for RF/Microwave applications," John Wiley and sons, Inc, 2001.

[2] Kishor Kumar Adhikari and Nam Young Kim, "A miniaturized quad-band bandstop filter with high selectivity based on shunt-connected, T-shaped stub-loaded, stepped-impedance resonators," Microwave Optical Technology Letters, vol. 57, no. 5, pp. 1129-1132, 2015.

[3] Gyan Raj Koirala and Nam-Young Kim, "Compact and tunable microstrip tri-band bandstop filter incorporating open-stubs loaded stepped-impedance-resonator,” Microwave Optical Technology Letters, vol. 59, no. 4, 2017.

[4] Gorur A. K., Basmaci Filiz AN., Dogan E., Karpuz C., Gorur A., "Dual-mode dual-band microstrip bandstop filter design with independently tunable center frequencies," Microwave Optical Technology Letters, vol. 59, pp. 2542-2547, 2017.

[5] G. Murat Eryilmaz, Elif Gunturkun, Adnan Gorur and Ceyhun Karpuz, "Microstrip bandstop filter using a dualmode square loop resonator," Microwave Optical Technology Letters, vol. 51, no. 1, 2009.

[6] Liang Liu, Rong-Hong Jin, Cheng Zhang, Jun-Ping Geng and Xian-Ling Liang, "A novel dual-band bandstop filter based on parallel stub-loaded resonator," Microwave Optical Technology Letters, vol. 58, no. 6, 2016.

[7] Nurshamimi Rosli, Siti Aminah Md Akhir, Siti Zuraidah Ibrahim, Nur Baya Mohd Hashim, Nurehansa fwanah Khalid, "Design of compact multi-mode microstrip resonator filters for dual-band application," Indonesian Journal of Electrical Engineering and Computer Science (IJEECS), vol. 13, no. 2, pp. 696-701, Feb 2019.

[8] G. R. Koirala and N. Y. Kim, "Multiband bandstop filter using an I-stub-loaded meandered defected mi crostrip structure," Radio Engineering, pp. 61-66, 2016.

[9] D. H. Werner and R. Mittra, "Frontiers in Electromagnetics," Piscataway, NJ: IEEE Press, pp. 48-81, 2000.

[10] Federico Caramanica, "Microstrip multistop band filter based on prefractal space-filling curve," Microwave Optical Technology Letters, vol. 56, no. 2, Feb 2014.

[11] Xu He-Xiu, Wang Guang-Ming, Yang Zi-Mu, "Dual-band left- handed metamaterials fabricated by using treeshaped fractal," Chin. Phys. B, vol. 21, no. 12, 2012.

[12] J. M. Patin, N. R. Labadie and S. K. Sharma, "Investigations on an H-fractal wideband microstrip filter with multipassbands and a tuned notch band," Progress in Electromagnetics Research B, vol. 22, pp. 285-303, 2010.

[13] José I. A.Trindade, Paulo H. da F. Silva, Antonio L. P. S.Campos and Adaildo G.D Assunção, "Analys is of stopband frequency selective surfaces with dürer's pentagon pre-fractals patch elements," IEEE Transactions on Magnetics, vol. 47, no. 5, May 2011.

[14] H. S. Ahmed, A. J. Salim and J. K. Ali, "A Compact dual-band bandstop filter based on fractal micro- strip resonators," Progress in Electromagnetics Research Symposium, PIERS 2015, Prague, Czech Republic, Jul 2015.

[15] H. S. Ahmed, A. J. Salim and J. K. Ali, "A Compact triple band BSF design based on Minkowski fractal geometry," 18th IEEE Mediterranean Electrotechnical Conference, MELECON 2016, Limassol, Cyprus, 2016. 
[16] H. S. Ahmed, et al., "A Fractal-based Dual-mode Microstrip Bandstop Filter for Wireless Applications" 16th Mediteranean Microwave Symposium (MMS), IEEE, 2016.

[17] H. S. Ahmed, J. K. Ali and A.J. Salim, "Design of Fractal- Based Bandstop Filter for Microwave Radiati on Leakage Reduction,” Engineering and Technology Journal, vol. 35, Part A, no. 1, pp. 16-23, 2017.

[18] Yaqeen S. Mezaal, Hiba H. Saleh and Hussam Al-saedi, "New Compact Microstrip Filters Based on Quasi Fractal Resonator," Advanced Electromagnetics, vol. 7, no. 4, Sep 2018.

[19] Benoit B. Mandelbrot, The fractal geometry of nature, New York: W. H. Freeman and Company, 1983.

[20] Nikolina Janković, B Vesna Crnojević- Bengin, "Balanced bandpass filter based on square patch Resonators," 12th International Conference on Telecommunication in Modern Satellite, Cable and Broadcasting Services- Nis, Serbia IEEE, 2015.

\section{BIOGRAPHIES OF AUTHORS}

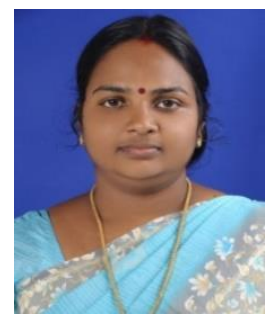

Manju Bhaskar was born on March $6^{\text {th }}, 1980$ in Kochi, Kerala. She received her bachelor's degree in Electronics and Communication Engineering in 2001 from, School of Engineering, Cochin University of Science and Technolgy, Kochi, Kerala, and master's degree in Electronics and Communication with specialization in Optoelectronics and Optical communication from Department of Optoelectronics, Kerala University in 2008. She worked as faculty and Head of the Department of Electronics and Communication, KMEA Engineering College, Kochi, India from 2002 to 2018. She is a faculty of MGM College of Engineering and Technology, Kochi, India and is pursuing her research in Microwave Electronics at School of Technology \& Applied Sciences, Mahatma Gandhi Univerisity Regional Center, Edappally, Kochi.Her current areas of research includes $\mathrm{RF} /$ microwave filters for wireless and telecommunication applications.

Tel: (+91) 9495232324

Email: sudheeshmanju@gmail.com

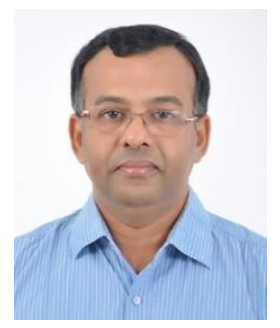

Thomaskutty Mathew was born in Kerala, India on 30th May 1967. He received his Ph.D Degree in Microwave Electronics from Cochin University of Science and Technology Cochin, India in 1997. From 1995 to 1999 he worked as a Lecturer in Physics at Christ College, Irinjalakuda, India. Since 1999, he is working as faculty of the Department of Electronics, School of Technology \& Applied Sciences, Mahatma Gandhi University Regional Center, Edappally, Kochi, India and presently working as Reader in the Department. During the period 2006-2008, he worked as a Post Doctoral Research Associate at Department of Electronics, University of Kent, Canterbury, U.K. His current area of research activites are in Microstrip antennas, Radar Cross Section, RFID, Wireless Sensor Networks etc. He is a member of IEEE Antennas and propagation society and IET (U.K).

Tel: (+91) 9048108856

E-mail: drtkmathew@gmail.com 